

\section{O ensino da cidade pelo uso das geotecnologias}

\section{La enseñanza de la ciudad a través del uso de las geotecnologías \\ Teaching the City Using Geotechnology}

Ana Claudia Ramos Sacramento*

\section{Resumo}

Pensar o uso das geotecnologias no ensino de Geografia cada vez mais tem sido uma necessidade mediante as diferentes formas de compreender o espaço geográfico que se vive, pois por meio da educação geográfica, podemos compreender a realidade local, a paisagem e suas diferentes transformações, ler os objetos que estão espacializados para decodificar diferentes mensagens, contextualizar informações, para analisar e perceber o espaço vivido, neste artigo, a cidade do Rio de Janeiro. O ensinar a cidade e o urbano como um conteúdo, nos possibilita contribuir com a formação cidadã do estudante na compreensão do lugar vivido por meio de suas práticas sociais espaciais. Este estudo fez parte da pesquisa do Projeto Universal: Um estudo sobre as didáticas e as concepções de cidade e de urbano dos alunos e professores de Geografia da cidade de São Gonçalo, financiada pelo CNPq período 2013-2016. Desta maneira, o objetivo deste texto é refletir sobre a Educação Geográfica, sob a perspectiva da utilização de Tecnologias da Informação e Comunicação -as TIC-, a fim de melhorar o processo de ensino e aprendizagem, a partir do portal EOUrbana, no qual possuem imagens, mapas e vídeos sobre a cidade do Rio de Janeiro em diferentes momentos históricos. A partir do estudo da cidade do Rio de Janeiro por meio de novas tecnologias, podem-se desenvolver diferentes maneiras de mediar o conhecimento geográfico.

\section{Palavras-chave}

ensino de Geografia; geotecnologias; cidade.

\footnotetext{
* Professora da UERJ-FFP.
} 


\section{Resumen}

Pensar el uso de las geotecnologías en la enseñanza de la geografía cada vez más ha sido una necesidad mediante las diferentes formas de comprender el espacio geográfico que se vive, pues a través de la educación geográfica podemos comprender la realidad local, el paisaje y sus diferentes transformaciones, leer los objetos que están espaciados para decodificar diferentes mensajes, contextualizar informaciones, para analizar y percibir el espacio vivido. La enseñanza de la ciudad y lo urbano como contenido, nos permite contribuir a la formación ciudadana del estudiante en la comprensión del lugar vivido por medio de sus prácticas sociales espaciales. Este estudio forma parte de la investigación del Proyecto Universal: Un estudio sobre las didácticas y las concepciones de ciudad y lo urbano de los alumnos y profesores de Geografía de la

\section{Abstract}

Thinking about the use of geotechnology in Geography teaching has been a necessity through the different ways of understanding the geographic space that is lived, because through geographic education, we can understand the local reality, the landscape and its different transformations, read the objects that are spatialized to decode different messages, to contextualize information, to analyze and perceive the lived space, in this article, the city of Rio de Janeiro. Teaching the city and the urban as a content allows us to contribute to the citizen's formation of the student in the understanding of the place lived through his social space practices. This study was part of the research of the Universal Project: A study on the didactics and conceptions of city and urban of the ciudad de São Gonçalo, financiada por el CNPq en los años 2013-2016. De esta manera, el objetivo de este texto es reflexionar sobre la Educación Geográfica, desde la perspectiva de la utilización de Tecnologías de la Información y Comunicación - las TIC -, a fin de mejorar el proceso de enseñanza y aprendizaje a partir del portal EOUrbana, el cual posee imágenes, mapas y videos sobre la ciudad de Río de Janeiro en diferentes momentos históricos. A partir del estudio de la ciudad de Río de Janeiro por medio de nuevas tecnologías, se pueden desarrollar diferentes maneras de mediar el conocimiento geográfico.

\section{Palabras clave}

enseñanza de geografía; geotecnologías; ciudad. students and professors of Geography of the city of São Gonçalo, financed by the CNPQ period 2013-2016. In this way, the objective of this text is to reflect on Geographic Education, from the perspective of the use of Information and Communication Technologies - ICT -, in order to improve the teaching and learning process from the EOUrbana portal, which has images, maps and videos about the city of Rio de Janeiro at different historical moments. From the study of the city of Rio de Janeiro through new technologies, different ways of mediating geographic knowledge can be developed.

\section{Keywords}

geography teaching; geotechnology; city. 


\section{Educação geográfica na perspectiva da utilização das geotecnologias}

A escola constitui lugar de reflexão acerca da realidade, seja esta local, regional, nacional ou mundial, uma vez que aquela fornece aparato instrumental capaz de permitir a este, a construção de uma visão organizada e articulada do mundo. Nesta perspectiva, as ações didáticas devem ser concebidas a partir de usos de diferentes tecnologias, que intervenham nas atividades de ensino e de aprendizagem, e que possibilitem articulações conceituais sobre os processos educativos.

Dentre as tecnologias que o ser humano inventou, estão algumas que afetaram profundamente a educação: a fala baseada em conceitos, a escrita alfabética, a imprensa, o conjunto de tecnologias eletroeletrônicas, que a partir do século passado começaram a afetar nossa vida de forma quase revolucionária, por meio da: fotografia, o cinema, a rádio, a televisão e o vídeo; hoje todas elas digitalizadas e integradas no computador.

Todas essas tecnologias estão sendo expostas e construídas também para se pensar que tipo de escola e que tipo de educação podem permitir um acesso ao educando. Sabemos que a escola não é somente aquela que transmite uma informação, pois esses recursos principais: a impressa, o rádio, TV e computador hoje exercem um poder sobre todos. Contudo, a forma como se codifica e interpreta esse conhecimento está vinculada não só à construção na escola, às suas políticas educacionais e suas concepções didático-pedagógicas, como também de infraestrutura.

Kenski (2007) argumenta que as Tecnologias da Informação e Comunicação correspondem a todas as tecnologias que interferem e mediam os processos informacionais e comunicativos. Ainda podem ser entendidas como um conjunto de recursos tecnológicos integrados entre si, que proporciona por meio das funções de hardware, software e telecomunicações, a automação e comunicação dos processos de negócios, da pesquisa científica e de ensino e aprendizagem.

Esse conjunto possibilita a intervenção na lógica de se pensar um determinado conteúdo ou conceito, a partir da consciência de como operacionalizar esses recursos, criando um processo de análise e de interpretação das informações, estimulando a capacidade do aluno de assimilar as mudanças das novas formas de aprender. Para tanto, o professor tem um papel importante nesse processo, como mediar o aluno e o recurso a ser utilizado, para que aquele pense sobre os diferentes significados das informações.

Ainda para Kenski (2008), com as TICs é possível pensar a forma da interação entre o conhecimento e a construção individual e social, uma vez que os ambientes digitais oferecem novos espaços e tempos de conexão com a informação e com a comunicação entre o docente e o estudante.
A função das tecnologias não é revolucionar o ensino ou a educação como um todo, seu objetivo é alterar a forma como a tecnologia é utilizada para a mediação entre os docentes, os estudantes e a informação.

As novas tecnologias exigem que o professor reavalie seu trabalho, tendo como foco o processo ensino-aprendizagem em geografia a todo o momento, buscando um aprendizado significativo constante, visto que aquelas existem para somar, ampliar e diversificar as formas de ensinar e aprender geografia, oferecendo aos docentes oportunidades de produzir aulas que possam dialogar com os conteúdos ensinados com uma perspectiva mais próxima à realidade dos estudantes.

Segundo Di Maio e Setzer (2011), os estudantes ao terem contado com os novos recursos tecnológicos, como a internet, a multimídia e os meios digitais, podem desenvolver novas formas de ler, escrever, observar, analisar e, desta maneira, de pensar e agir sobre um determinado objeto do conhecimento.

Contudo, as tecnologias não modificam a prática docente, servem, na verdade, para uma mediação diferenciada do conhecimento -a depender de seu uso por parte do docente-, pois para Kenski (2008), a importância das TICs está no processo de ação colaborativa no ensino, pressupondo, assim, que haja circulação intensa de informações e trocas, visando ao alcance dos objetivos previstos.

Os novos processos de interação e comunicação no ensino mediado pelas tecnologias visam ir além da relação entre ensinar e aprender. Orientam-se para a formação de um novo homem: autônomo, crítico, consciente da sua responsabilidade individual e social; enfim, um novo cidadão para uma nova sociedade. Pode-se dizer que são recursos com linguagens ou formas digitais que têm materiais e linguagens diferenciadas, permitindo, assim, novas maneiras de armazenamento de dados e informações.

A Geografia Escolar contemporânea tem como característica a leitura e interpretação do saber sobre o espaço geográfico em suas diferentes escalas de análises. Sendo assim, deve propiciar ao aluno a leitura e a compreensão dos conceitos. O desenvolvimento das tecnologias da informação possibilitou o registro de informações geográficas em forma digital, aumentando a quantidade de recursos disponíveis, como os Sistemas de Informações Geográficas, os jogos digitais, as simulações, entre outros.

A leitura de mundo precisa de códigos, signos e linguagens, estando aquela, em nosso caso, ligada aos conceitos e conteúdos da Geografia. Segundo Santos (1996), as revoluções técnicas presididas pela comunicação e pelos computadores, impulsionaram um novo olhar sobre as redes, consequentemente, sobre o espaço geográfico.

Para Munhoz (2006), pensar na aplicabilidade das TICs na educação geográfica é mais que unicamente apresentar aos estudantes, mas sim, 
relacionar o ensino e a aprendizagem significativa ao uso de recursos, para articular os diversos conhecimentos de forma interativa, ou seja, as diferentes formas que incluem desde o potencial de entretenimento, colaboração, interação, dentre outras características próprias de uma tecnologia, até a definição de quais conceitos serão trabalhados, passando em seguida ao planejamento, escolha dos objetivos a serem alcançados, metodologia e quais recursos digitais servirão a este intento.

Desta maneira, para a autora, compreender a nova geração, como pensa e interage de acordo com o mundo a sua volta, é difícil, tendo em vista a complexidade do mundo atual, onde grande parte das relações interpessoais não acontece apenas pelo contato pessoal. Também por uma infinidade de artefatos eletrônicos, mídias e redes sociais, que diminuem as distâncias, facilitam a vida, e inserem outro ritmo de tempo para resolução de tarefas, tornando aparentemente simples algo antes complexo, principalmente para aqueles que dominam este conhecimento.

Assim, na educação geográfica, as TICs ajudam os estudantes tanto a compreenderem a sua realidade, a paisagem e suas transformações, como também o espaço geográfico de forma criativa e prazerosa, pois estas estão cada dia mais passando a fazer parte da vida dos alunos, tornando-se um excelente instrumento para os docentes realizarem seu trabalho em sala de aula de forma mais inovadora e dinâmica, uma vez se utilizadas de modo correto e coerente com as necessidades educacionais.

A Educação Geográfica tem grande importância nessa forma de ler os objetos digitais, pois se a leitura do mundo perpassa pela decodificação de mensagens, da articulação e contextualização das informações, a geografia escolar possibilita essa análise, a assimilação pela leitura do espaço e de seus diferentes conceitos e, também, por meio de outras linguagens, sabendo assim, lidar com novos instrumentos e construir novas formas de analisar e perceber o espaço vivido.

Desta maneira, os conhecimentos didático-pedagógicos são relevantes para se pensar os caminhos, os meios e as formas de como estabelecer a relação entre o conhecimento e os alunos. As ações didáticas permitem que os professores escolham, de acordo com suas realidades, quais serão as condições para orientar a construção do conhecimento dos fenômenos geográficos.

\section{O ensino da cidade por meio da geotecnologia}

o estudo da cidade representa novas experiências de trabalho a respeito da vida cotidiana dos alunos e a forma como interpretam tal realidade. Por meio dos conceitos e dos conteúdos vinculados à cidade e ao urbano, procurou-se pensar em diferentes materiais para se trabalhar com essa temática, de maneira a estimular o conhecimento do estudante.
Pensar a cidade e o urbano como um conteúdo do ensinar Geografia nos possibilita contribuir com a formação cidadã do estudante ao permitir a este a compreensão do lugar vivido por meio de suas práticas sociais espaciais. Outra questão está pautada nas relações globais e locais que caracterizam hoje os espaços; em um mundo onde os fluxos e as redes se estabelecem com rapidez, o significado de estudar a cidade e o urbano faz com que o estudante reflita sobre aquilo que acontece na sua cidade, os problemas urbanos, os problemas ambientais, as questões econômicas, os fluxos e as redes, os aspectos físicos, suas paisagens, seus patrimônios históricos, seus arranjos territoriais, que muitas vezes não são articulados no cotidiano escolar.

Compreender como funciona a cidade é para Sposito (2008) um fenômeno complexo e que, ao mesmo tempo, está em constante movimento, pois se transforma de acordo com diferentes lógicas, tanto políticas, como econômicas -sociais-. A cidade não só vive todos os dias mudanças que são fruto dos interesses e das ações das corporações e da sociedade, também processos contraditórios das práticas espaciais de viver e estar na cidade, -as formas de apropriação e controle dos espaços por diferentes atividades, e formas de uso por sujeitos sociais e individuais, e as grandes corporações que se materializam no espaço da cidade.

Assim, a fim de desenvolver um modo de pensar geográfico, é preciso que os estudantes, ao lidar com os signos e representações, formem conceitos que instrumentalizem esse pensamento. Esses conceitos permitem aos alunos localizarem-se e darem significado aos lugares e as suas experiências sociais e culturais, na diversidade em que elas se realizarem.

Segundo Santos (1996), podem-se construir conceitos de localização, estudo do relevo e análise do espaço urbano, além da identificação, leitura e análise espacial de vários objetos do arranjo ou os objetos técnicos, como os prédios e as avenidas, assim como a natureza, a água, o solo, as formações vegetais e tantos outros elementos que fazem parte do cotidiano do aluno.

A cidade, em suas múltiplas relações sociais, econômicas, históricas e geográficas em constante transformação, exige uma compreensão contínua da organização e estruturação das novas dinâmicas do espaço. A cidade representa a obra da história construída por seus sujeitos, ou simplesmente, a ação da sociedade que vive, produz e reproduz esse espaço (Lefebvre, 2001).

Para dar caráter científico ao mundo em que vivemos, os conceitos são primordiais para os alunos se desprenderem do senso comum e contemplarem as concepções geográficas sobre determinados objetos e lugares.

Perceber um fenômeno em sua dimensão geográfica é assim primeiramente localizar, distribuir, conectar, medir a distância, delimitar a extensão e verificar a escala de sua manifestação na paisagem. A forma como o fenômeno aparece no espaço é a do 
objeto espacial, a exemplo da fábrica no fenômeno econômico, da igreja no fenômeno cultural e do parlamento no fenômeno político. Todo conhecimento em geografia por isso começa na descrição da paisagem. (Moreira, 2008, pp. 116-117).

Para ler os fenômenos, os alunos precisam ter uma lógica de organização da aprendizagem e realizar algumas etapas de como eles percebem as diferentes formas de análise sobre uma dada realidade. Desta maneira, é importante que as ações didáticas dos professores estejam sempre direcionadas a pensar na construção dos conceitos, já que possuem elementos cognitivos necessários para entendê-los. Segundo Moreira (2008), para se conhecer a Geografia, é preciso fazer a descrição da paisagem, pois é a partir dela que vamos desvendar os outros aspectos característicos do espaço, já que a paisagem é a materialização concreta dos fenômenos e dos objetos.

Estudar esses fenômenos a partir do uso de geotecnologias implica compreender como ocorre a dinâmica de construção do conhecimento geográfico, que neste trabalho, caracteriza-se pelo conhecimento acerca da cidade do Rio de Janeiro e suas formas e conteúdos, com as novas tecnologias que se inserem na medida em que estão relacionadas com diferentes formas de ver o mundo, de aprender novos conceitos e receber informações. Sousa e Jordão afirmam:

A introdução das geotecnologias em meio digital no processo de ensino e aprendizagem de Geografia desperta maior interesse e, por conseguinte motiva o aluno apreender a realidade geográfica por meio de informações mais atualizadas ou em tempo real do espaço geográfico e, sobretudo devido ao uso da tecnologia computacional que é contemporânea a ele. (Sousa e Jordão, 2015, p. 154)

O interesse é notório quando nas aulas de Geografia, as simulações aparecem e podem ser analisadas, como era, por exemplo, o espaço geográfico antes e depois; como as paisagens mudam e permanecem; os diferentes momentos tempo-geográfico, e outros, que permitem uma discussão sobre a importância de compreender as dinâmicas sócioespaciais.

\section{0 uso do portal como forma de compreensão da cidade do Rio de Janeiro}

a partir do estudo da cidade do Rio de Janeiro, por meio de novas tecnologias, pode-se desenvolver outra forma de mediar o conhecimento através do site desenvolvido pelo Instituto Municipal de Urbanismo Pereira Passos (IPP) ${ }^{1}$ em que estão localizados dados de análises, pesquisas e projetos, mapeamentos digitais e base de dados da cidade do Rio de

1 Data de recuperação: http://portalgeo.rio.ri.gov.br/
Janeiro, com informações também sobre Cartografia e Geoprocessamento da cidade. Esses materiais sobre a cidade do Rio de Janeiro foram produzidos por conta do Programa Estadual de Despoluição da Baía de Guanabara, em 1995, em que o instituto produziu uma série de dados e informações com mapas e vídeos para conhecimento sobre a cidade.

Para este trabalho será apresentado o Portal EOUrbana ${ }^{2}$, no qual traz de forma dinâmica alguns pontos e diferentes paisagens acerca da cidade do Rio de Janeiro ao longo do tempo. As atividades sobre a discussão da urbanização são realizadas nas turmas do $2^{\circ}$ ano no Ensino Médio, pois o Currículo Mínimo de Geografia apresenta, no $2^{\circ}$ bimestre, o tema: Urbanização Mundial e Brasileira. 0 que se busca fazer é a relação entre as escalas, partindo da discussão do estado e da cidade do Rio de Janeiro e de São Gonçalo. Na entrada do site, há um quadro com a evolução e ocupação da cidade, além de um "mapa do site", em que se encontram dois eixos: ilustrações e mapas. Na ilustração está descrito "um passeio no tempo", o qual tem cinco pontos específicos da cidade do Rio de Janeiro: Arcos da Lapa, Praça XV, Largo da Carioca, Porto do Rio e Copacabana.
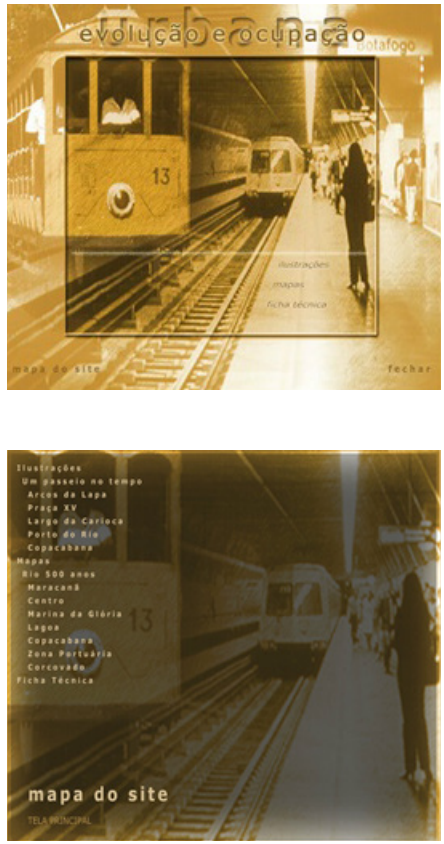

Imagens 1 e 2: Apresentação do site com os recursos apresentados

$\mathrm{Na}$ apresentação, ao clicar em um ponto, por exemplo, Copacabana, será demostrado um vídeo em que retrata os diferentes tempos e espaços deste bairro. O vídeo apresenta o Rio de Janeiro em quatro momentos: em 1893, 1927, 1956, 2007, ou seja, as diferentes fases do bairro de Copacabana, destacando as mudanças e permanências nesta paisagem,

2 Data de recuperação: http://portalgeo.rio.rj.gov.br/EOUrbana/ 
a forma como esta se manifesta como uma representação da essência que se transfigura na aparência das coisas que muitas vezes não são vistas como tal.
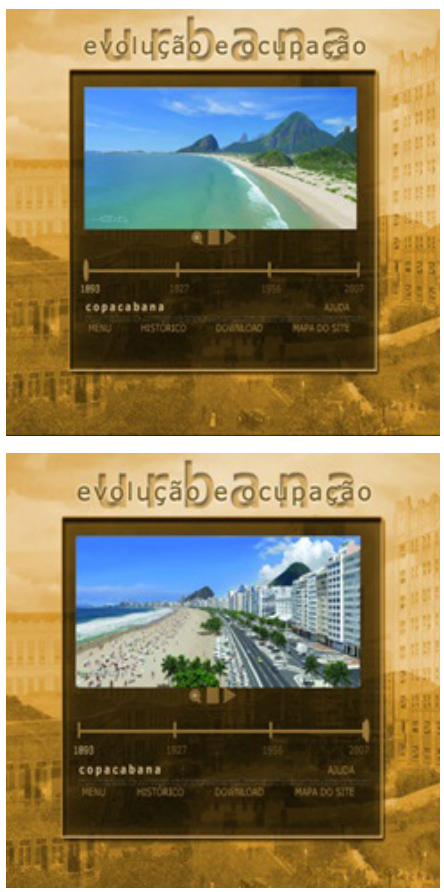

Imagens 3 e 4: Apresentação do vídeo de diferentes momentos de Copacabana

A partir de 1893, como apresentado no vídeo, vê-se o início da expansão da cidade do Rio de Janeiro para outras partes, principalmente, visto ser este o momento em que ocorre a grande obra urbana: a Reforma de Pereira Passos, com as mudanças arquitetônicas e urbanísticas, com a malha urbana se expandindo para além do centro da cidade em direção à Zona Norte, como os bairros de São Cristóvão e Tijuca; também para a Zona Sul, com os bairros Glória, Catete, Flamengo, Botafogo e Copacabana (Abreu, 2011).

No decorrer do século XX, o desenvolvimento industrial e o próprio processo de modernização urbana aceleraram as transformações, estimulando a imigração para a cidade do Rio de Janeiro. As mansões da Zona Sul, por exemplo, foram substituídas por apartamentos e condomínios. Adicionalmente, um processo de verticalização acelerada foi notado em Copacabana, assim como a infraestrutura, por conta do aumento populacional (Abreu, 2011).

De forma a mostrar como a técnica está articulada ao modo de pensar e agir do ser humano, faz-se necessário ver a concepção desse termo, que para Santos (1996, p. 25) é, "um conjunto de meios instrumentais e sociais, com os quais o homem realiza sua vida, produz e ao mesmo tempo, cria espaço". Isto porque a técnica exprime a arte do ser humano em criar e recriar objetos, concepções, expressando sua cultura, sua inteligência, sua emoção, dando personificação a este objeto que se tornou técnico.

Os objetos técnicos precisam estar relacionados às relações sociais que os criaram, e estas se materializam no campo da configuração territorial. Esta é construída de acordo com a necessidade que o ser humano tem em materializar o natural em artificial. Esta artificialidade é a técnica que o homem vem adquirindo ao longo do tempo, e que o espaço vai arrumando de forma a dar vida a uma nova configuração territorial. No vídeo, observa-se e analisa-se como se materializa territorialmente as mudanças do natural-artificial por conta da necessidade ao longo da história, pela ocupação da cidade do Rio de Janeiro, e consequentemente da zona sul.

Nas imagens 5 e 6, a utilização dos textos e dos materiais impressos pode também ser trabalhada, como as imagens em papel, articulando conteúdos como: a) relacionar os acontecimentos do passado e do presente; b) observar, a partir do observável, o que supostamente seria a paisagem natural e o que foi humanizado; c) analisar a interferência do homem e a modificação deste lugar, a partir da construção de diferentes objetos; d) analisar o processo de urbanização do bairro; e) trabalhar o conceito de lugar, paisagem, natureza e espaço.

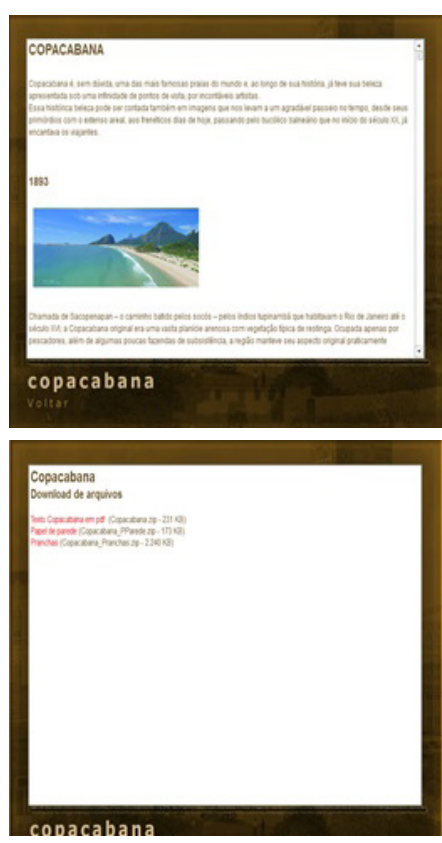

Imagens 5 e 6: Texto sobre Copacabana e download dos materiais para papel. 
Na parte "Mapas", há a descrição do Rio em 500 anos com os seguintes pontos: Maracanã, Centro, Marina da Glória, Lagoa, Copacabana, Zona Portuária e Corcovado. Neste mapa tridimensional apresenta-se o relevo original do lugar, e a partir da passagem do vídeo as transformações na paisagem, ocorridas ao longo do tempo, são visualizadas. Há uma apresentação em vídeo, na qual o mapa é passado do ano 1500 ao ano 2000, mostrando como a evolução geomorfológica da cidade foi se constituindo. Neste momento, trabalha-se as formações de relevo com os estudantes.

O trabalho ocorre pela exemplificação de como o Rio de Janeiro vem sendo uma das primeiras cidades nacionalmente constituídas, que começa a ser ocupada nos mais diferentes pontos; que sofreu grandes transformações no final do século XIX, na década de 1950 (Abreu, 2011), e a partir de 2010, com a questão das Olimpíadas.
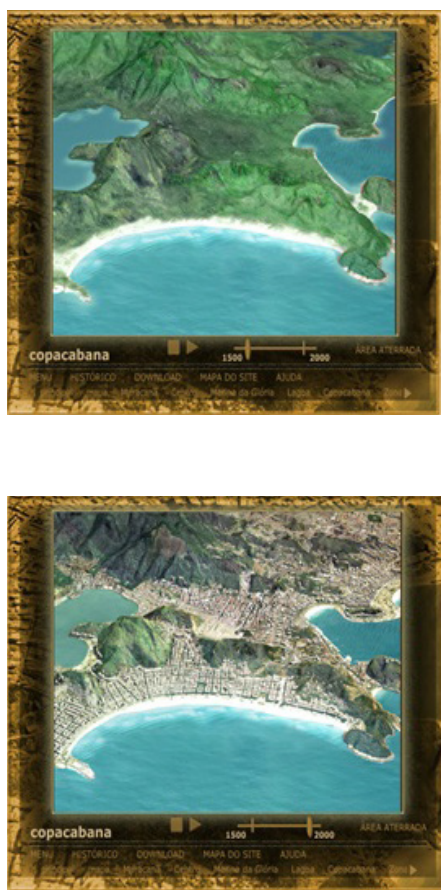

Imagens 7 e 8: Transformações na paisagem de Copacabana

Ao se trabalhar com a evolução geográfica do bairro de Copacabana, tem-se o objetivo de analisar como a cidade do Rio de Janeiro passou por diversos processos de transformações. Para Santos, o conceito de paisagem é "um conjunto de formas que, num dado momento, exprimem as heranças que representam as sucessivas relações localizadas entre homem e natureza" (Santos, 1996, p. 83). Assim, mudanças que o homem exerce através das contradições que se configuram em uma relação com ele mesmo, com os outros e com a Natureza, é "a história congelada, mas participa da história viva. São as suas formas que realizam, no espaço, as funções sociais” (Santos, 1996, p. 86). Desta maneira, ao trazer este pequeno vídeo, mostra-se para os estudantes as diferentes relações tempo-espaço que o bairro de Copacabana viveu e vive com as diversas etapas do desenvolvimento tecnológico, econômico, social, político e cultural. Além da constituição física, pode-se visualizar as diferentes formas geomorfológicas e geológicas que possibilitaram a cidade ter uma paisagem que vislumbre os maciços litorâneos, planícies, Baía de Guanabara, lagoas, restingas, ilhas e praias, que foram modificadas pelo crescimento acelerado da cidade e pela ocupação de forma desordenada.

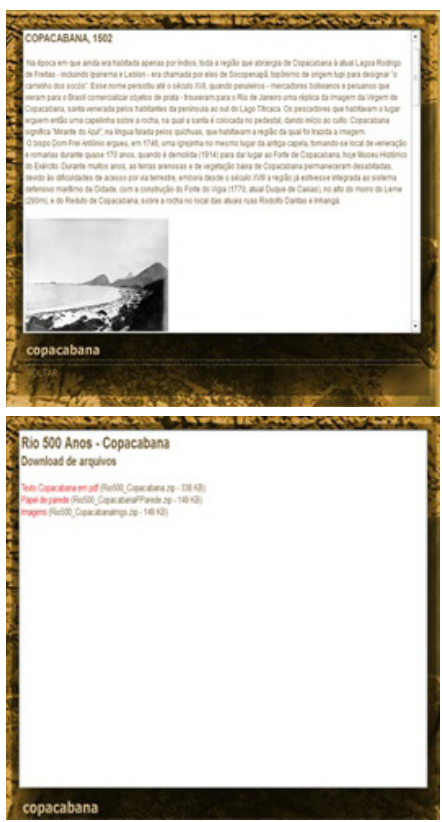

Imagens 9 e 10: Texto sobre Copacabana e download dos materiais para papel.

Ao clicar no link "histórico", é apresentado um texto contando a história do bairro a partir do vídeo apresentado. Além disso, na parte "download", pode-se ter acesso ao papel do texto, ao papel de parede e à prancha do lugar escolhido. Com os textos digitais ou em papel, pode-se desenvolver algumas dinâmicas; como o uso das imagens de modo a entender a estruturação da cidade e de seu crescimento urbano ao longo do século XX.

Assim, várias temáticas podem ser trabalhadas: a) as paisagens natural e urbana - as mudanças ou as permanências que se deram: pelo processo histórico-geográfico (ou seja, eles precisam entender o contexto e os meios de cada época); b) o processo de urbanização e de ocupação; c) o uso de diferentes técnicas (pois as imagens apresentavam casas, depois, prédios com determinados estilos e atualmente, edifícios com tipos de materiais diferenciados); d) a verticalização e horizontalidade; e) a infraestrutura; f) as formas e os conteúdos dos objetos, pela necessidade social das pessoas; $\mathrm{g}$ ) as diferentes mobilidades das pessoas (dos 
cavalos, das carretes, dos bondes aos carros); h) as mudanças no relevo, bacia hidrográfica e solo, para o desenvolvimento do assentamento humano; j) as desigualdades sócioespaciais e as áreas da sociedade e l) planejamento urbano; entre outros.

\section{Considerações finais}

A escola, em sua grande maioria, está distanciada da realidade cotidiana dos alunos que usam outros espaços cibernéticos para se comunicarem, mas por vezes, não fazem uso científico ou escolar para a construção do conhecimento. Portanto, torna-se relevante o planejamento didático, o pensar as novas metodologias, e objetivos e funções da Geografia atual, por meio da educação geográfica. A formação docente precisa estar relacionada com a preparação dos conhecimentos pedagógicos e específicos, para que a aprendizagem, a didática, a metodologia e o currículo, não sejam um simples "passar" do conteúdo, mas desenvolva no profissional o prazer de realizar seu trabalho, possibilitando o progresso escolar do aluno.
Pensar as geotecnologias como forma de articular outras metodologias pode contribuir para a construção do conhecimento do estudante, e promover a criação e recriação dos conceitos e dos conteúdos sobre a cidade, para conduzir uma aprendizagem mediada, a partir de atividades que produzam a assimilação e o equilíbrio de novos conceitos devido às formas de utilização das novas tecnologias, aliadas à discussão sobre a cidade, constituindo uma leitura de mundo por meio da Educação Geográfica.

Ensinar a cidade do Rio de Janeiro com a utilização do recurso digital é uma forma de se desenvolver vários conteúdos e conceitos, em uma outra perspectiva, com outros materiais, além do livro didático, do quadro e do giz. A intenção de trazer para o debate como se trabalhar o estudo da cidade do Rio de Janeiro, a partir das geotecnologias, mostra diferentes formas de se lidar com os conceitos e conteúdos geográficos, articulados com materiais que trazem possibilidades de mediar o conhecimento.

\section{Referências}

Abreu, M. de A. (2011). A evolução urbana do Rio de Janeiro. (4a ed). Rio de Janeiro: IplanRIO.

Di Maio, A. C., e Setzer, A. W. (2011) Educação, Geografia e o desafio de novas tecnologias. Revista Portuguesa de Educação 24, 211-241.

Kenski, V. (2007). Educação e tecnologias: o novo ritmo da informação. (2a ed.). Campinas: Papirus.

Kenski, V. (2008). Novos processos de interação e comunicação no ensino mediado pelas tecnologias. São Paulo: Pró-Reitoria de Graduação-USP. Recuperado em 25 de maio, 2016, de http://www.prg.usp.br/wp-content/ uploads/vani_kenski_caderno_7.pdf.

Moreira, R. (2008). Conceitos, categorias e princípios lógicos para o método e o ensino de geografia. In: R. Moreira (org.). Pensar e ser em geografia: ensaios de história, epistemologia e ontologia do espaço geográfico. (2a ed., pp. 105-118). São Paulo: Contexto.

Munhoz, G. B. (2006). A aprendizagem da Geografia por meio da Informática Educativa. Dissertação de mestrado, Faculdade de Educação da USP, São Paulo, SP, Brasil.

Lefebvre, H. (2001). O Direito à Cidade. São Paulo: Centauro.

Santos, M. (1996). Natureza do Espaço: técnica e tempo, razão e emoção. São Paulo: Hucitec.

Sousa, I. B., e Jordão, B. G. F. (2015). Geotecnologias como recursos didáticos em apoio ao ensino de Cartografia nas aulas de Geografia do Ensino Básico. Caminhos de Geografia (UFU), 16, 150-163. Recuperado em 06 de junho, 2016.

Sposito, E. S. (2008). Redes e cidades. São Paulo: Unesp. 